\title{
The Rising of a New Dawn in Africa: An Introduction to the African Continental Free Trade Area
}

\author{
Perry Ackon $^{1 *} \quad$ Victoria Ackon ${ }^{2}$ \\ 1.PhD Candidate in International Law, School of Law, Xiamen University, \\ No. 422, Siming South Road, Xiamen, Fujian, China. 361005 \\ 2.LLM Student in International Law, School of Law, Xiamen University, \\ No. 422, Siming South Road, Xiamen, Fujian, China. 361005
}

\begin{abstract}
There is a rising of a new dawn in African trade. The trade pattern of this region is set to change by the introduction of the African Continental Free Trade Area. This legal trade agreement moved by the African Union seeks to increase Intra - African Trade by creating a single market and allowing a free flow of people and goods has been postulated to curb the abnormality of ascending trading figures among African countries with countries from other continents as compared to the abysmal figures of trade among African countries. This academic piece seeks to unveil the African Continental Free Trade Area by highlighting its constituents, major strengths, challenges, expected impact and what it means for the international trading community. This academic piece seeks to present a simplified introduction to this agreement.
\end{abstract}

Keywords: Intra - Africa, Trade agreement, Single market and Sustainable development.

DOI: $10.7176 / \mathrm{JAAS} / 54-08$

Publication date: April $30^{\text {th }} 2019$

\section{Introduction}

The role of partnerships in the development of a nation can never be under estimated. The ability of a nation to strike the right partnerships in trade and other sectors of development opens the doors for economic growth and the right support for the elimination of barriers and challenges to other facets for sustainable development. The presence of bilateral and multilateral investments treaties among many other trade inclined treaties speaks volumes to this effect. The very idea of a dual benefitting partnership provides countries who are lacking in certain prospects of either the process of manufacturing or acquiring raw materials to receive the needed support to enhance the development of their nation through enhanced productivity.

Ghana and the Ivory Coast stand as the highest producing countries of cocoa beans in the world but in the absence of trade partnerships with foreign countries majority of the beans produced would go to waste due to the absence of processing and manufacturing industries in both countries. The highlight of every partnership in this regard is in the mutual benefit of all transactions. In this regard African countries have been on the trailing end as many of the trade deals with foreign companies and organizations literally leave these African countries for dead with no major strides in development. It is worth noting that not all of these partnerships have yielded bad results, some of these partnerships have not only brought outstanding benefits but have also opened major doors for the African countries to be training and developed to perform that very task for which the partnership was initiated. The advancement of global trade has seen Africa countries trade more with foreign groups, countries and organizations more than fellow African countries. A report by the UN body, UNCTAD, on economic and trade activities in the African continent provided the mind blowing fact that all intra-trading activities on the African continent amounted to only $10.2 \%$ of all trading activities. ${ }^{1}$ Catching the attention of the AU, the society delivered a vivid response by the adoption and signing of the African Continental Free Trade Area whose major goals are to enhance intra-African trade by creating a single market within the African continent and allow the free flow of goods, services and people within the continent. ${ }^{2}$

\section{The African Continental Free Trade Area}

The AU which serves as the major organization to facilitate the integration of African countries and to present a united front in the pursuit of common goals in its dealings have signed ten major agreements with partners, organizations and countries. ${ }^{3}$ The Africa-Arab partnership, Africa-European Union (EU) Partnership, AfricaSouth America (ASA) Summit, The Africa-India Cooperation Agreement, The Africa-Turkey Partnership, China-Africa Cooperation Forum (FOCAC), Africa-United States, Tokyo International Conference on African Development (TICAD), The Korea-Africa Forum and The Africa-Australia partnership. These are all major

\footnotetext{
${ }^{1}$ UNCTAD Economic Development in Africa Report 2013, INTRA-AFRICAN TRADE: UNLOCKING PRIVATE SECTOR DYNAMISM. UNCTAD/ALDC/AFRICA/2013. ISSN 1990-5114.

${ }^{2}$ The objectives of the African Continental Free Trade Area. Retrieved 01/04/2019. https://au.int/en/ti/cfta/about

${ }^{3}$ AU Partnerships. Retrieved 01/04/2019. https://au.int/en/continent-and-country-partnerships
} 
trade treaties signed by the AU over the years to enhance the economy and trading activity on the continent. In the light of these signings and opportunities, intra-trade between African countries have been on the down-hill as it has only amassed as low as $10.2 \%$ of all trading activities involving the continent. ${ }^{1}$ To the above effect the birth of the African Continental Free Trade Area. In order to salvage the situation of intra trading by African Countries, in 2012 African heads of state agreed to establish a continental free trade area and in 2015 deliberations and negotiations began to realize this goal. ${ }^{2}$ The agreement which is aimed at increasing the percentage of trading activities between African countries seeks to mainly liberalize trading services with the aim of tackling "non-tariff" barriers which hinder trading activities between African countries via long delays and complicated processes. The agreement which was expected to be signed by all fifty five member states of the African Union will certainly bring a great swing to the intra trading activities between African Countries due to the combine efforts of 1.2 billion people who possess of a gross domestic product of more than 2 trillion. In retrospect, the draft agreement is geared at driving signatory states to commit to the removal of tariffs on ninety percent of goods with the remaining ten percent representing sensitive goods that will be phased in later. ${ }^{3}$ The agreement which is being classified by many renowned economists as what Africa needs to heighten intra trading activities is also believed to in the near future be utilized as a tool for the free movement of people and even a single currency for the African continent with as part of the free trade area agreements.

\section{The impact of the African Continent Free Trade Area}

Though many have lauded the initiative by the African Union to materialize this agreement one question lingers on the mind of many, what is going to be the impact of this agreement? Is it going to be another white elephant? Or is Africa going to harness its great potential by the implementation of this agreement. The impact of the African Continental Free Trade Area in simple terms is to ensure and encourage effective trade between African countries. How will this work? What factors are going to be put into place so as to ensure its achievements? And finally how will these factors workout for the realization of its objectives? The agreement is being initiated with full recognition of the need to cover all legal grounds. Hence, vivid documentation on how events within the initiative like dispute settlement, treatment of nations and other required laid down means for an effective operation have been well outlined in its treaty. ${ }^{4}$

\subsection{Trade alliance of African Nations.}

The foremost factor that comes to play in the light of this agreement is the very idea of creating a single continental market for goods and services. The African continent on its own can boost of producers of raw materials and also industries with equal efficiency in the manufacturing and processing of raw materials as Western countries. Currently forty four of the fifty five member states of the African Union have signed unto the agreement with twenty one of the forty four ratifying the agreement. ${ }^{5}$ Benin, Botswana, Eritrea, Guinea-Bissau, Nigeria, and Zambia are the only countries that have not signed unto the agreement. ${ }^{6}$ The agreement if fully fledged will be a powerful force in the sphere of trade.

\subsection{Reduction of costs.}

The reduction of these tariffs and the elimination of some basic taxes within the African continent will not only bring about the reduction of production costs but will also enable a huge access market within the African continent for the trading of goods and services. Furthermore it is no secret that in pursuit of reduced cost of production, African countries where raw materials are produced and could have equally found processing industries within Africa, decide to export these raw materials to countries outside the continent. The volatile nature of the export and import market leave these African countries at the peril of these foreign countries. This is literally shown by the presence of unemployment and drastic results in reports concerning sustainable development in some African countries where some of the most staple raw materials are being produced. The establishment of this agreement will certainly place Africa in the right position for further development and increased productivity as costs would be reduced by way of duties and tariffs. ${ }^{7}$

\footnotetext{
${ }^{1}$ UNCTAD Economic Development in Africa Report 2013, INTRA-AFRICAN TRADE: UNLOCKING PRIVATE SECTOR DYNAMISM. UNCTAD/ALDC/AFRICA/2013. ISSN 1990-5114.

${ }^{2}$ Information on the formation of the African Continental Free Trade Area. Retrieved 01/04/2019. https://au.int/en/ti/cfta/about

${ }^{3}$ AU Q\&A on ACFTA. Retrieved 01/04/2019. https://au.int/sites/default/files/documents/33984-doc-qa cfta en rev15march.pdf

${ }^{4}$ The Treaty on the AfCFTA. Retrieved 02/04/2019. https://au.int/sites/default/files/treaties/34248-treaty-consolidated text_on_cfta_en.pdf

5 Signatories to the AfCFTA Treaty. Retrieved 02/04/2019. https://au.int/sites/default/files/pressreleases/34033-prindication20of20signing20authority20-20updated20final20final20docx.pdf

Uwiringiyimana, Clement. "Nigeria keen to ensure Africa trade bloc good for itself: president". Reuters. March 21, 2018.https://www.reuters.com/article/us-africa-trade/africa-agrees-to-giant-trade-bloc-but-nigeria-south-africa-sit-it-out-idUSKBN1GX29V

${ }^{7}$ PART III under PROTOCOL ON TRADE IN GOODS, LIBERALISATION OF TRADE. https://au.int/sites/default/files/treaties/34248treaty-consolidated text on cfta - en.pdf
} 


\subsection{Elimination of restrictions.}

Finally, the very notion of a continent with so much restrictions defeats the vision of the African Union. The Union as part of its duties carries a vision of regional integration of the African Continent. In its operation the Union must spearhead the removal and correction of some restrictions within the African continent that do not only place physical frustrations in the plight of trading but also mentally dumbfound the idea of Unity. A fringe benefit of this trade agreement will certainly be its impact on the sense of unity and ones that has been sort by afore leaders within the African continent like Kwame Nkrumah, the first president of the republic of Ghana.

\subsection{Implementation}

The whole idea of the initiative is to simplify trading activities among African nations hence if the procedure for implementation is too cumbersome that by itself would be a problem. On that note the AU has opted for a more simplified approach of utilizing three main spheres; The AfCFTA Secretariat, The regional economic communities (RECs) and The AfCFTA Committee of Senior Trade Officials. The Secretariat is solely responsible for the coordination of the whole initiative as the Regional economic communities (RECs) is responsible for implementation at the regional levels. The AfCFTA Committee of Senior Trade Officials is in charge of ensuring the harmonization of standard and monitoring implementations. Along with these sectors is a broad outline and a mapping out of the initiative according to country profiles according to National AfCFTA strategies. ${ }^{1}$

\section{The Challenges of this Agreement.}

The plaque of challenges rising in the face of positive and great initiatives is highly metaphorical of the night appearing before sun rise. Amidst the glorious opportunities that the AfCFTA agreement will bring to the international African community by way of economic and financial development some challenges that seek to impede its successful impact linger within its administrative and operational enforcement. Though the trade agreement from a holistic perspective can be seen as a major positive, there are still some negatives by way of organization and enforcement. Some questions that have been posed by scholars and other nation building stakeholders include issues of security, checks and balance, and dumping. This concern has also been shared by some of the governments of the African nations as some have decided not to sign unto the agreement. Nigeria, an economic power house in Africa, is one of the countries that have not signed unto the agreement. This challenge can pose as a major threat to the sustenance and success of the initiative.

\subsection{Security}

The issue of security cannot be left out with regards to the deliberations concerning the African Continental Free Trade Agreement. Security has been the center of many discussions in recent times as the advent of many mischievous trade deals have not only sabotaged some level of development bust has brought about some setbacks in government initiatives and quest for sustainable development. The ability to ensure the security of all the nations duly engaged in the agreement will not only be a major achievement but would also serve as a means by which confidence is built for the development of Africa by way of investments. Security has been one major impeding factor to development on the African continent. By way of political instability and many others development has been stalled in many African states. To effectively implement this free trade agreement the security of the nations must be duly considered and right fully so aspects under the agreement treaty highlight security exceptions. ${ }^{2}$

\subsection{Checks and balance.}

It would be a statement of total ignorance to neglect the efforts made to ensure the unity of the African continent by way of trade and investment in the past. Many agreements have been made to aide in the integration of African countries but have failed because they lacked checks and balance to ensure progress and maintenance. The institution of checks and balances to fully coordinate the operations and effectiveness of agreements and policies have been one of the major headaches of the African continent. What would be the use of an industrious policy if it would not serve any good and rather be a burden a few years down the lane? Checks and balances would be of huge importance.

\subsection{Dumping}

The opening of boarders and lowering of tariffs over the years to foster trade has positively correlated with the increase in the dumping of goods of mostly inferior quality into countries. The essence of the trade agreement is to ensure that all countries within Africa benefit from the enhanced trade activities via the free trade agreement

\footnotetext{
${ }^{1}$ AU Q\&A on ACFTA. Retrieved 01/04/2019. https://au.int/sites/default/files/documents/33984-doc-qa_cfta en rev15march.pdf

${ }^{2}$ Article 27 in the AfCFTA treaty. AGREEMENT ESTABLISHING THE AFRICAN CONTINENTAL FREE TRADE AREA. Retrieved 2/04/2019. https://au.int/sites/default/files/treaties/34248-treaty-consolidated text on cfta - en.pdf
} 
by way of the exchange of quality goods useful for the development of their economy. The core of the practice of dumping is the influx of goods that do not benefit the country but rather become a burden. This being one of the major challenges if permitted will not deter states from signing the trade agreement but will also negatively impact the economic developments of the countries already signed unto the agreement. ${ }^{1}$

\section{Impact beyond Africa}

The success of this trade agreement will definitely be a win for Africa as it would boost intra African trades and investments. As it stands now majority of the trade and investment deals between African states are much lower compared with deals involving African countries and countries off the shores of Africa. This literally means that more money is leaving the shores of Africa to Europe, Asia, the Americas... etc. than the money circulating among African countries for the development of the continent. This needs to be rectified hence the need for the African continental free trade area. The success of the agreement will boost the industries within the continent and will further expand the supply chain of goods and services flowing within the continent. The impact beyond Africa is inevitable as dealings with countries outside Africa amount to $89.8 \%$ of all trading activities in Africa. The resources that would have left the shores of Africa will remain in Africa and there will certainly be a reduction in returns from trade with African nations for countries outside. In the long run it will sure serve a greater advantage as Africa will be more equipped to contribute to global development.

\section{Conclusion}

Africa since time memorial has been the feeding grounds for many nations other than itself. This initiative if well implemented will duly serve a great purpose in the wake ensuring development on the continent of Africa. Implementation is at the core of every success of any initiative and this is no different. The story will not be any different from the other integrative policies that have been put forward in Africa that have failed if this agreement is not duly implemented. In conclusion, the advent of this trade agreement must not necessarily spell doom and gloom for trade and investment of African nations with other countries outside the continent. This calls for smart and wise trade efforts so as to effectively balance trade by African countries with fellow African countries and trade with countries off the shore of the continent. This must not be done to the demerit of the African continent.

\section{Reference}

AfCFTA Anti-dumping regulations, Article 17, AfCFTA Treaty. PROTOCOL ON TRADE IN GOODS. https://au.int/sites/default/files/treaties/34248-treaty-consolidated text on cfta - en.pdf

AU Partnerships. Retrieved 01/04/2019. https://au.int/en/continent-and-country-partnerships

AU Q\&A on ACFTA. Retrieved 01/04/2019. https://au.int/sites/default/files/documents/33984-docqa cfta_en rev15march.pdf

Article 27 in the AfCFTA treaty. AGREEMENT ESTABLISHING THE AFRICAN CONTINENTAL FREE TRADE AREA. Retrieved 2/04/2019. https://au.int/sites/default/files/treaties/34248-treatyconsolidated text_on_cfta_-_en.pdf

Information on the formation of the African Continental Free Trade Area. Retrieved 01/04/2019. https://au.int/en/ti/cfta/about

PART III under PROTOCOL ON TRADE IN GOODS, LIBERALISATION OF TRADE. https://au.int/sites/default/files/treaties/34248-treaty-consolidated text_on_cfta_-_en.pdf

Signatories to the AfCFTA Treaty. Retrieved 02/04/2019. https://au.int/sites/default/files/pressreleases/34033-prindication20of20signing20authority20-20updated20final20final20docx.pdf

The objectives of the African Continental Free Trade Area. Retrieved 01/04/2019. https://au.int/en/ti/cfta/about

The Treaty on the AfCFTA. Retrieved 02/04/2019. https://au.int/sites/default/files/treaties/34248-treatyconsolidated text on cfta_- en.pdf

Uwiringiyimana, Clement. "Nigeria keen to ensure Africa trade bloc good for itself: president". Reuters. March 21, 2018. https://www.reuters.com/article/us-africa-trade/africa-agrees-to-giant-trade-bloc-but-nigeriasouth-africa-sit-it-out-idUSKBN1GX29V

UNCTAD Economic Development in Africa Report 2013, INTRA-AFRICAN TRADE: UNLOCKING PRIVATE SECTOR DYNAMISM. UNCTAD/ALDC/AFRICA/2013. ISSN 1990-5114.

\footnotetext{
${ }^{1}$ AfCFTA Anti-dumping regulations, Article 17, AfCFTA Treaty. PROTOCOL ON TRADE IN GOODS https://au.int/sites/default/files/treaties/34248-treaty-consolidated text on cfta - en.pdf
} 